\title{
BMJ Open Characteristics of heart failure patients incurring high medical costs via matching specific health examination results and medical claim data: a cross- sectional study
}

\author{
Yuya Tamaki, ${ }^{1}$ Kana Kazawa,${ }^{1}$ Hirohito Watanabe, ${ }^{1}$ Tantut Susanto (i) , 2 \\ Michiko Moriyama ${ }^{1}$
}

To cite: Tamaki Y, Kazawa $\mathrm{K}$, Watanabe $\mathrm{H}$, et al. Characteristics of heart failure patients incurring high medical costs via matching specific health examination results and medical claim data: a crosssectional study. BMJ Open 2019;9:e031422. doi:10.1136/ bmjopen-2019-031422

- Prepublication history for this paper is available online. To view these files, please visit the journal online (http://dx.doi. org/10.1136/bmjopen-2019031422).

Received 03 May 2019 Revised 14 October 2019 Accepted 25 November 2019

\section{Check for updates}

(c) Author(s) (or their employer(s)) 2019. Re-use permitted under CC BY-NC. No commercial re-use. See rights and permissions. Published by BMJ.

${ }^{1}$ Graduate School of Biomedical and Health Sciences, Hiroshima University, Hiroshima, Japan

${ }^{2}$ Community, Family, Geriatric Nursing, Universitas Jember, Jember, Jawa Timur, Indonesia

Correspondence to

Dr Kana Kazawa;

kkazawa@hiroshima-u.ac.jp

\section{ABSTRACT}

Objective We describe the characteristics of patients with high medical costs by matching specific annual medical examination results and medical claim data. Clarifying the relationships between examination items and high medical costs allows the screening of high-risk persons.

Design A cross-sectional study.

Subjects Subjects were persons insured by national health insurance in Hiroshima City, Hiroshima Prefecture, from April 2016 to March 2017. To identify true heart failure (HF) patients, the disease name listed in the medical claim data was compared with drugs prescribed for HF, with extraction of only subjects whose comparative data matched.

Data collection and analysis The specific health examination includes a questionnaire on areas such as lifestyle habits, anthropometry, blood pressure, blood tests and urine tests. The percentage of the total medical costs related to the medical care of subjects with $\mathrm{HF}$ was described using Pareto analysis. For specific health examination items, we compared the high-cost and lowcost groups. The normality and homoscedasticity of each variable was checked and Student's t-tests and $\chi^{2}$ tests were applied. Finally, multiple logistic regression analysis was used to detect factors in the health examination items related to high medical costs.

Results Pareto analysis showed that $80 \%$ of all medical costs were paid by $30 \%$ of the HF patient population. The fees for cardiovascular surgery accounted for $54 \%$ of the total surgical cost, $64 \%$ of which included preventable diseases. Levels of creatinine $(\mathrm{Cr})$ and $\gamma$-glutamyl transpeptidase $(\gamma$-GTP) and a history of smoking were found to be related to high medical costs.

Conclusion Analysis of specific health examination results for HF patients revealed the association between high medical costs, $\gamma$-GTP, $\mathrm{Cr}$, and smoking. These results can thus serve as a reference for screening persons at high risk of $\mathrm{HF}$ and help prevent the exacerbation of HF.

\section{INTRODUCTION}

Heart failure (HF) constitutes a serious problem worldwide due to its high prevalence and places a burden on families and health
Strengths and limitations of this study

- To ensure the reliability of the data used in analysis, the disease name as listed in the medical claim data was compared with the drugs prescribed for HF, and only those subjects for whom the comparative data matched were extracted.

- Analysis matching medical costs for HF patients with the specific examination results enables the clarification of the relationships between users with high medical costs and specific health examination items.

- Our limitations relate to the generalisability of our study's analysis results, as subjects were limited to beneficiaries of National Health Insurance and their ages to 40 to 74 years, the eligible age-range for specific medical examinations.

due to its high mortality rate and medical costs. $^{1-3}$ Approximately 979000 people in Japan were diagnosed with HF in 2005, and given Japan's ageing population, HF patients are projected to increase to 1.3 million by 2030. ${ }^{1}$ Meanwhile, although certainly not in all cases, $\mathrm{HF}$ is a preventable pathology with acute exacerbation. Hence, early diagnosis of risk factors by healthcare providers is crucial to taking appropriate measures to prevent or delay the onset of $\mathrm{HF}^{4}$ The advantages of prevention services for $\mathrm{HF}$ have been reported in the Netherlands, ${ }^{5}$ where a screening programme for chronic diseases implemented among residents diagnosed $44 \%$ of the respondents with $\mathrm{HF}$, leading to optimal treatment. Given the rise in general life expectancy plus the increasing hospitalisation rates for $\mathrm{HF}$, the establishment of new healthcare delivery system models that effectively control HF risk factors is required for 
timely care to prevent hospitalisations and to postpone HF-related deaths. ${ }^{2}$

In Japan, medical insurers are obliged to monitor the health conditions of their beneficiaries. Therefore, medical insurers perform health promotion and lifestyle health check-ups to identify people at risk of developing metabolic syndrome. Persons eligible for check-ups provided by medical insurers are the insured and their dependents aged between 40 to 74 years old. Although decisions regarding which specific items to include on the check-up are left to the discretion of each local government, tests and examinations are carried out in accordance with Japanese law. ${ }^{6}$

One problem that the medical community has experienced is that there is no item on the 'specific health examination' (the term used for the examinations described above) to confirm HF biomarkers or any previous history of the condition. Therefore, opportunities to provide health guidance and consultations at medical institution for people screened with HF have unfortunately been missed. Initially, it is essential to include items related to $\mathrm{HF}$ on the specific medical examination. However, we first attempted to define the characteristics of those with HF based on the particular health examination items currently available. More than half of HF patients are latestage adults aged over 75 years, ${ }^{3}$ but early detection, early treatment, and management among young adults and during the first stage of older adulthood (40-74year-old patients) are essential to reduce severity and optimise medical costs. ${ }^{4}$

Therefore, this study aims to clarify the characteristics of HF patients incurring high medical costs by matching the disease name, medical records, medical fees, and specific health examination results. We believe that this is particularly relevant, as we can then establish new health guidance to clarify the characteristics of patients with $\mathrm{HF}$ in both low-cost and high-cost situations using detailed health examination results and health insurance claim data. As a cross-sectional study, this study aims to clarify the characteristics of patients with HF with reference to high medical costs resulting from the matching analysis of health insurance costs with specific health examination results, applying a specification of 'HF' as obtained in exploratory fashion from health insurance claim data. Furthermore, based on the resulting HF characteristics, we seek to clarify specific health examination results related to high medical costs, findings which can help to establish and improve systems to provide professional guidance to persons at high risk of HF.

\section{METHODS}

\section{Study design and subjects}

A cross-sectional study design was used to identify the characteristics of the patients with HF through a matching analysis of health examination results and health insurance claim data. As it is challenging to confirm a diagnosis of HF using medical claims, subjects were considered HF patients if they had a history of using diuretics or beta blockers. Pharmacological treatment was used as a criterion to confirm HF, because, in Japan, oral diuretics and beta-blockers are recommended for HF treatment. ${ }^{7}$

In order for subjects to be eligible for enrolment in this study, we set the following criteria: 1) Persons who had National Health Insurance in Hiroshima City, Hiroshima Prefecture, from April 2016 to March 2017, and who were diagnosed with HF according to the International Classification of Diseases (ICD 10 code: I 500 Congestive heart failure, I 509 Heart failure, I 501 Left heart failure, I 110 Hypertensive heart disease with heart failure, I 099 Rheumatic heart failure) in medical claims, and used the drugs prescribed for HF. The disease name listed on detailed examination information forms (herein called 'medical claim data') is not necessarily the true name of the diagnosed disease, as a temporary name is often used for laboratory and other testing purposes; 2) persons incurring high medical costs aged from 40 to 74 years; 3) persons who were either self-employed, working in agriculture or fisheries, part-time workers, or unemployed. Subjects without an HF diagnosis were excluded from our study based on the disease name stated on the medical claims and their non-use of HF therapeutic agents.

\section{Procedure for data collection and target selection}

The variables of interest were the core items of the specific health examination. These core items include a questionnaire on areas such as lifestyle habits, anthropometry (height, weight, body mass index (BMI), abdominal circumference), blood pressure, blood tests (complete blood count, lipids, liver and kidney function and blood glucose (glycaemia or HbAlc)), and urine tests (glycosuria and proteinuria). National Health Insurance in Hiroshima City provided coverage for a total of 203782 persons aged 40-74 years old. Of this number, $6577(3.2 \%)$ met the operational definition of HF and were included in the sample for this study (figure 1).

Pareto analysis was conducted to identify the highcost group; after sorting the costs in descending order from high to low, the ratio of accumulated costs to total costs was calculated. In addition, the percentage of the cumulative number of participants vs the total number of participants was calculated. Pareto analysis is used in the medical field to clarify how much a portion of high-level elements contributes to the whole. ${ }^{8}$

This group incurred $80 \%$ of all medical costs, and $30 \%$ $(1,979)$ of the patients with HF accounted for $80 \%$ of all medical costs associated with HF. Based on these observations, we divided medical costs into two groups: a 'highcost group' consisting of 1979 insured patients (30\%) who used $80 \%$ of all medical costs, and the remaining 4598 users (20\%), classified as the 'low-cost group' (figure 1).

In addition, we extracted health check-up data from both of these groups. As a result, 99 subjects from the high-cost group and 539 subjects from the low-cost group were included in our analysis. We compared and analysed the health check-up results for these two groups. 


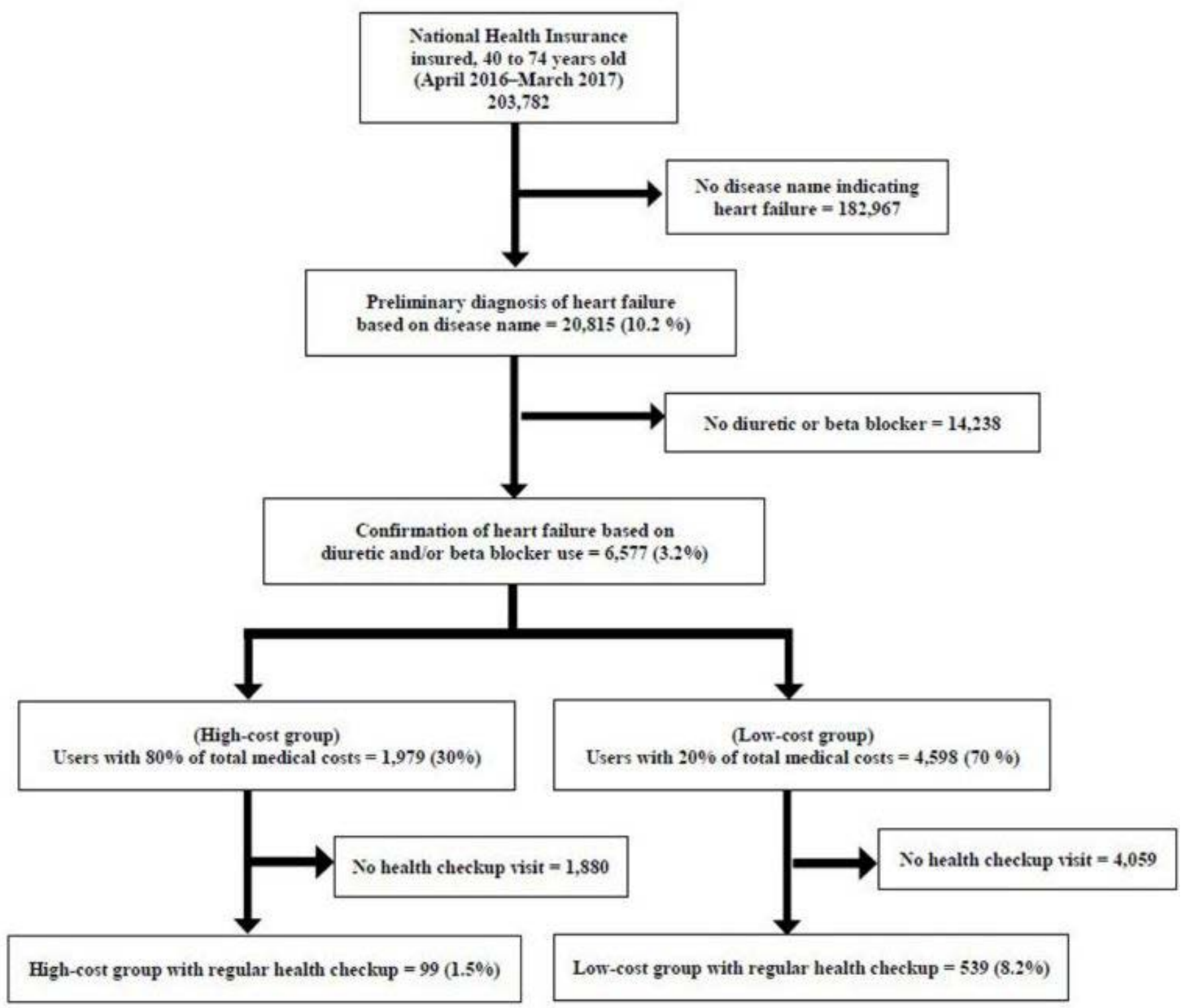

Figure 1 Sample framing.

Patient and public involvement

No patients were involved.

\section{Ethical considerations}

The insurer of Hiroshima City provided us with data, and the analysis was conducted on an opt-out basis. The optout information was posted from the Hiroshima University website to public domain. For medical insured persons (Hiroshima City), in conformance with the City's Personal Protection Regulations, this study was performed as a joint study with Hiroshima University as a part of the city's healthcare policies. Approval for this study was obtained from the ethics committee of Hiroshima University. Analysis results will be published in scientific papers and given to the beneficiaries as demanded.
Data analysis

Analysis of medical costs using health insurance claim data

The percentage of the total medical costs related to the medical care of subjects with HF was determined using Pareto analysis. Pareto analysis techniques were used to rearrange total medical-care cost data in descending order and calculate the ratio of increasing value to total cost. Based on the results of the Pareto analysis, high-spending medical care beneficiaries were defined as those incurring the top $80 \%$ of medical costs, henceforth called the 'high-cost group', and beneficiaries incurring the lowest $20 \%$ of medical costs under the category 'consumers' comprised the low-cost group.

Differences by age between the low-cost group and the high-cost group were compared with a Student's t-test, whereas differences by gender were examined with a $\chi^{2}$ test. We classified the subjects as either 'older adults' (subjects aged 65 to 74) or 'young adults' (those aged 40 
to 64 years old), and compared the names of the main diseases of hospitalisation in the low-cost and high-cost groups. Mann-Whitney's U test was used to compare medical costs (annual medical costs by hospitalisation/ outpatient, annual hospitalisation days, number of outpatient days, and yearly medical costs by clinical practice).

\section{Analysis of specific health parameters and clinical biomarkertest} results

We compared the high-cost and low-cost groups for specific health examination items. In our analysis, we examined the normality and homoscedasticity of each variable and used Student's t-test and $\chi^{2}$ test. Finally, multiple logistic regression analysis was used to determine factors from the health examination items related to high medical costs. In the selection of independent variables, after omitting variables with many missing points, multiple collinearities were assessed beforehand in an interphase matrix, and variables showing a Pearson's correlation coefficient of 0.8 or more were excluded. The dependent variables were the group (1: high-cost group; 0: low-cost group), and the independent variables were body mass index (BMI), systolic blood pressure, smoking, glutamic pyruvic transaminase (GPT), $\gamma$-glutamyl transpeptidase $(\gamma$-GTP), creatinine $(\mathrm{Cr})$, urine protein, blood glucose, and haemoglobin $(\mathrm{Hb})$. For adjustment of confounding factors, age and gender were input as independent variables and analysed. For statistical analysis, IBM SPSS Statistics version 25 was used, and the significance level was set at $5 \%$.

\section{RESULTS}

\section{Overall medical cost analysis of patients with HF}

The mean age of the low-cost group was $67.2 \pm 6.7$, which was similar to that of the high- cost group ( $66.8 \pm 6.9$ years old; $\mathrm{p}=0.036$ ). There were more male subjects in the low-cost group $(\mathrm{n}=2792 ; 61 \%)$ than the high-cost group $(\mathrm{n}=1292 ; 65 \% ; \mathrm{p}<0.001)$. Pareto analysis showed that $80 \%$ of all medical costs were incurred by $30 \%$ of the total HF patients. Annual outpatient expenditure was 1872911 230 yen $(32.8 \%)$ in the low-cost group and 3843802 000 yen $(67.2 \%)$ in the high-cost group. Annual hospitalisation cost was 332751660 yen $(6.3 \%)$ in the low-cost group, whereas it was 4985365300 yen (93.7\%) in the high-cost group.

The median annual hospitalisation cost per capita was 350350 yen ( $\mathrm{IQR}=177650-608470)$ in the low-cost group, and 2115750 yen (IQR=1 $215560-3765070)$ in the high-cost group $(\mathrm{p}<0.001)$.

Similarly, the number of median annual days of hospitalisation per capita was significantly higher $(\mathrm{p}<0.001)$ in the high-cost group (29 days $(\mathrm{IQR}=13-63)$ ) than in the low-cost group ( 6 days $(\mathrm{IQR}=3-13)$ ).

Median annual outpatient cost per capita was 351030 yen $(\mathrm{IQR}=223820-533280)$ in the low-cost group and 953020 yen $(\mathrm{IQR}=460630-3,091,660)$ in the high-cost group ( $\mathrm{p}<0.001)$. Median annual days of outpatient visits per capita for the low-cost group was estimated at 19 days $(\mathrm{IQR}=12-32)$, whereas in the high-cost group it was significantly higher $(\mathrm{p}<0.001)$ at 35 days $(\mathrm{IQR}=20-90)$.

The results of aggregating the number of hospitalised disease names in the low-cost group and the high-cost group in elderly and young people are as follows.

In the high-cost group, regardless of age, the top three diseases were cardiovascular disease, neoplasm, and urogenital disease. In the low-cost group, cardiovascular disease was the most common disease suffered by both age groups. In the younger age group of the low-cost group, subjects also suffered from endocrine, nutritional, and metabolic diseases (second-highest) and digestive system diseases (third-highest), while the older age group of the low-cost group suffered from digestive system diseases (second-highest) and neoplasms (third-highest). figure 2 shows the annual total medical costs by medical service for the low-cost and high-cost groups. The most significant part of the medical costs by medical service was surgery fees (595872810 yen) for the high-cost group and examination fees (340529360 yen) for the low-cost group. Although the proportion of emergency/intensive care fees in the high-cost group as a whole is not high, this group accounted for $90.3 \%$ of the total number of patients who underwent emergency care.

\section{Analysis of specific health parameters and clinical biomarkers} Table 1 shows the specific health parameters and clinical biomarkers after excluding items that had high defect rates and could not be analysed. The specified medical examination rate of National Health Insurance beneficiaries of Hiroshima City was $15.9 \%$. The specific medical examination rate of all $\mathrm{HF}$ patients, who are the subjects of this study, was $9.7 \%$. We noted differences in the clinical biomarkers of the high-cost and low-cost groups, with $\gamma$-GTP and Cr significantly higher in the high-cost group and haematocrit (Ht), Hb, and red blood cells (RBC) substantially lower in the low-cost group (table 1).

Table 2 also shows the results of multiple logistic regression analysis of the relationship between clinical biomarkers and HF among high medical cost subjects. After adjusting for confounders, $\mathrm{Cr}(\mathrm{OR}=2.367 \quad(95 \%$ CI 1.266 to 4.425$), \mathrm{p}=0.007), \gamma$-GTP $(\mathrm{OR}=1.006(95 \%$ CI: 1.002 to 1.010$), \mathrm{p}=0.003)$, and history of smoking $(\mathrm{OR}=6.914(95 \%$ CI 1.475 to 32.411$), \mathrm{p}=0.014)$ were significantly associated with high medical costs among patients with HF. Furthermore, to confirm how influential each related factor was, the dispersion ratios of $\gamma$-GTP and Cr, excluding smoking, were calculated on the nominal scale. Cr displayed a high degree of influence; $\gamma$-GTP showed an $F$-value of $4.55(\mathrm{p}=0.033)$ and $\mathrm{Cr}$ an $F$ value of $26.53(\mathrm{p}<0.001)$.

\section{DISCUSSION}

Pareto analysis of patients with $\mathrm{HF}$ aged 40 to 74 years revealed that $30 \%$ of these patients incurred $80 \%$ of all medical costs. This observation is similar to our recent study carried out in Japan reporting that $80 \%$ of total 


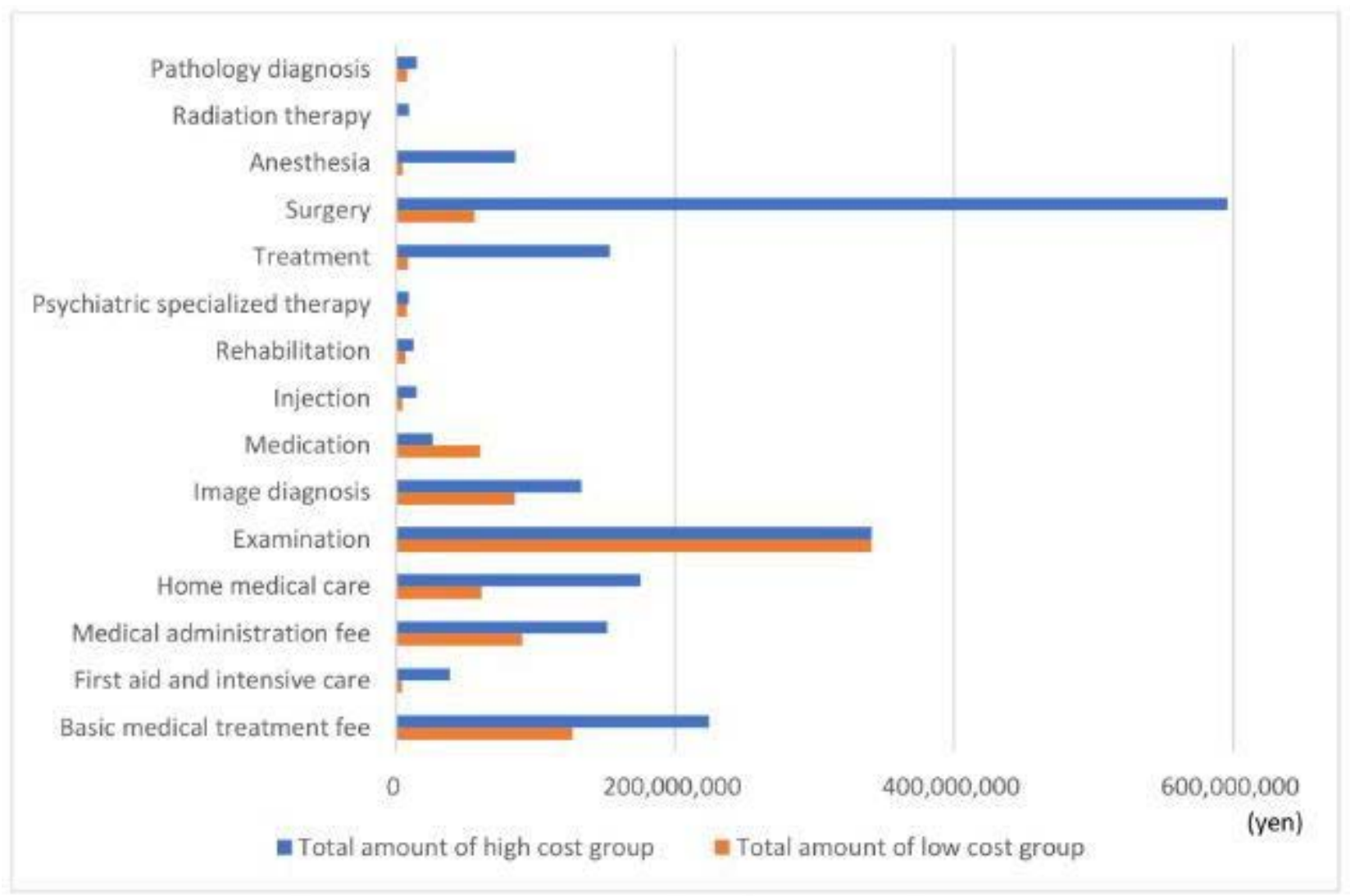

Figure 2 Total annual medical costs by medical services.

medical costs were channelled to $33 \%$ of patients. ${ }^{8}$ Assessing factors linked with higher costs in HF patients is important because it indicates interventions needed to reduce costs. Analysis of insurance claim data revealed that total medical costs due to hospitalisation of insured patients with HF were as high as expected. The high-cost group accounted for $93.7 \%$ of the total annual medical costs due to hospitalisation, suggesting that hospitalisation leads to high medical costs for beneficiaries. This means in theory that if healthcare professionals can prevent or reduce hospitalisation among HF patients by promoting, for example, outpatient pharmacotherapies, this would result in reduced medical costs for $\mathrm{HF}$ patients. As comorbidities in HF patients are common and are linked to higher hospitalisation risk, ${ }^{7}$ we analysed the claim data while considering the disease names that led to hospitalisation into consideration. This helped us identify, regardless of the age group, the top three major disease names that led to hospitalisation. Cardiovascular diseases accounted for about $30 \%$, whereas the remaining $70 \%$ were non-cardiovascular diseases. This finding is crucial, as it reminds healthcare providers to implement health education based on comorbidities; this has the potential to shorten hospital stay length and reduce the total costs incurred by HF patients.

Another important finding is that in the low-cost group, medical cost was driven by the examination procedures, whereas in the high-cost group surgery did so. As surgery necessitates hospitalisation, it increases service costs.
Another reason is that the re-hospitalisation rate from exacerbation of HF rapidly increases for patients over 75 years old, and intensive care management is required for acute exacerbations at 40 to 74 years of age. It is thus conceivable that medical costs are high due to the costs of surgery. This is in line with a previous report that medical costs related to intensive care for HF treatment are the most expensive. ${ }^{9}$

Based on these observations, we analysed details of surgical procedures which are considered causes of high medical costs. In the high-cost group, the number of cardiac/vascular surgeries was the highest at 680 (54\%). Furthermore, among the causes of cardiac and vascular surgery, the most common cause was arterial disease, followed by ischaemic heart disease; these top two diseases accounted for $64 \%$ of all major causes. Arteriosclerosis significantly contributes to the onset of these vascular diseases ${ }^{10}$ and can be prevented by management of risk factors. ${ }^{11}$ In particular, ischaemic heart disease, accounting for $30 \%$ of the total number of surgical cases, is a significant disease that causes HF. ${ }^{12}$ If these can be screened for, primary or secondary prevention would be possible. In turn, this would also lead to the optimisation of medical costs for patients.

Analysis of specific health examination results showed that $\gamma$-GTP and Cr were significantly higher in the highcost group, and $\mathrm{Hb}$ was lower in this group. Heart, kidneys, and anaemia are closely related, ${ }^{13}$ and chronic kidney disease $(\mathrm{CKD})$ is a predictor of severe $\mathrm{HF}^{14}$ In addition, 
Table 1 Baseline characteristics of specific medical examination results for HF patients in the high-cost group and the lowcost group Mean $\pm S D$

\begin{tabular}{|c|c|c|c|}
\hline & $\begin{array}{l}\text { High-cost group } \\
(\mathrm{n}=99)\end{array}$ & $\begin{array}{l}\text { Low-cost group } \\
(\mathrm{n}=539)\end{array}$ & $p$-value \\
\hline Age & $68.9( \pm 5.3)$ & $68.5( \pm 5.7)$ & $0.506^{\dagger}$ \\
\hline Sex (Male / female) $n(\%)^{*}$ & $63(64) / 36(36)$ & $315(58) / 224(42)$ & $0.334^{\ddagger}$ \\
\hline BMI & $23.3( \pm 3.4)$ & $24.0( \pm 3.7)$ & $0.083^{\dagger}$ \\
\hline $\mathrm{SBP}(\mathrm{mmHg})$ & $130( \pm 18)$ & $129( \pm 18)$ & $0.747^{\dagger}$ \\
\hline $\begin{array}{l}\text { Diagnosis of metabolic syndrome } \\
\text { (Applicable / reserve group) } n(\%)\end{array}$ & $35(35) / 10(10)$ & 191(35) / 63(12) & $0.892^{\ddagger}$ \\
\hline Smoking $n(\%)$ & $9(9)$ & $67(12)$ & $0.346^{\ddagger}$ \\
\hline $\mathrm{TG}(\mathrm{mg} / \mathrm{dl})$ & $142( \pm 89)$ & $139( \pm 88)$ & $0.814^{\dagger}$ \\
\hline $\mathrm{HDL}-\mathrm{C}(\mathrm{mg} / \mathrm{dl})$ & $60( \pm 22)$ & $60( \pm 17)$ & $0.919^{\dagger}$ \\
\hline LDL-C (mg/dl) & $114( \pm 43)$ & $113( \pm 31)$ & $0.656^{\dagger}$ \\
\hline GOT (IU/L) & $24( \pm 10)$ & $24( \pm 11)$ & $0.823^{\dagger}$ \\
\hline GPT (IU/L) & $20( \pm 12)$ & $21( \pm 13)$ & $0.220^{\dagger}$ \\
\hline$\gamma$-GTP (IU/L) & $64( \pm 101)$ & $47( \pm 68)$ & $0.033^{\dagger}$ \\
\hline $\mathrm{Cr}(\mathrm{mg} / \mathrm{dl})$ & $1.2( \pm 1.1)$ & $0.9( \pm 0.3)$ & $<0.001^{\dagger}$ \\
\hline $\mathrm{UA}(\mathrm{mg} / \mathrm{dl})$ & $5.7( \pm 1.4)$ & $5.8( \pm 1.4)$ & $0.433^{\dagger}$ \\
\hline FBS (mg/dl) & $114( \pm 34)$ & $108( \pm 25)$ & $0.110^{\dagger}$ \\
\hline $\mathrm{HbA1c}(\%)$ & $6.04( \pm 0.9)$ & $6.02( \pm 0.7)$ & $0.787^{\dagger}$ \\
\hline $\begin{array}{l}\text { Urinary protein } \\
( \pm / 1+/ 2+/ 3+) n(\%)\end{array}$ & $\begin{array}{l}13(13) / 7(7) / \\
9(9) / 4(4)\end{array}$ & $\begin{array}{l}78(14) / 34(6) / \\
23(4) / 8(3)\end{array}$ & $0.085^{\ddagger}$ \\
\hline $\mathrm{Ht}(\%)$ & $40.2( \pm 5.7)$ & $41.7( \pm 4.5)$ & $0.005^{\dagger}$ \\
\hline $\mathrm{Hb}(\mathrm{g} / \mathrm{dl})$ & $13.5( \pm 1.8)$ & $13.9( \pm 1.5)$ & $0.017^{\dagger}$ \\
\hline $\mathrm{RBC}\left(/ \mathrm{mm}^{3}\right)$ & $434( \pm 66)$ & $447( \pm 49)$ & $0.02^{\dagger}$ \\
\hline
\end{tabular}

${ }^{*}$ Data are displayed as $n(\%)$ or mean $(S D)$ unless otherwise noted.

†t-test,

$\ddagger$ Chi-squared test.

BMI, Body mass index; $\mathrm{Cr}$, Creatinine; FBS, fasting blood sugar; GOT, Glutamic Oxaloacetic Transaminase; GPT, Glutamic Pyruvic

Transaminase; $\gamma$-GTP, $\gamma$-glutamyl transpeptidase; $\mathrm{Hb}$, haemoglobin; $\mathrm{HbA1c}$, haemoglobin Alc;HDL-C, high density lipoprotein cholesterol; $\mathrm{HF}$, heart failure; Ht, haematocrit; LDL-C, low density lipoprotein cholesterol; RBC, red blood cells; SBP, systolic blood pressure; TG, triglyceride;

UA, Uric acid.

the coexistence of CKD increases the incidence of cardiac insufficiency and increases medical costs. ${ }^{15}$ Therefore, in HF patients, screening for those with CKD and lower $\mathrm{Hb}$ is considered of high importance. Since the present study was a cross-sectional analysis at a single time-point, the order of disease onset is not clear, but it is clear that HF is one cause of congestive hepatopathy. Liver dysfunction involving $\gamma$-GTP is related to increased cardiovascular events and mortality rates, making this an important index ${ }^{16}$; we consider this to have been extracted as a characteristic of patients with severe HF who have high medical costs and were subjects of this analysis.

Table 2 Related factors for HF patients using high medical costs

\begin{tabular}{llll} 
& Partial regression coefficient & Or (95\% Cl) & P value \\
\hline$\gamma$-GTP & 0.006 & $1.006(1.002$ to 1.010$)$ & 0.003 \\
Cr & 0.861 & $2.367(1.266$ to 4.425$)$ & 0.007 \\
Smoking & 1.934 & $6.914(1.475$ to 32.411$)$ & 0.014 \\
\hline
\end{tabular}

Multiple logistic regression analysis; Hosmer-Lemeshow test $\left(\chi^{2}\right)=3.644(\mathrm{p}=0.888)$; Cox and Snell $R^{2}=0.071$; Nagelkerke $R^{2}=0.121$, the discriminant predictive value was $84.2 \%$, and the goodness of fit was good. Data are displayed asn (\%) or mean (SD) unless otherwise noted. Using the likelihood ratio increase method, best fit regression equations and independent variables whichcomprise said regression equations are shown.

$\mathrm{Cr}$, Creatinine; $\gamma$-GTP, $\gamma$-glutamyl transpeptidase; HF, heart failure. 
Furthermore, multiple logistic regression analysis was performed to extract HF patient factors associated with high medical costs. Smoking has the highest OR and is a risk factor of $\mathrm{HF}^{17}$ suggesting that guidance on how patients can quit smoking should be considered an intervention measure.

$\mathrm{HF}$ is reported to impose an economic burden, its prognosis is poor, ${ }^{18}$ and it is detrimental to quality of life (QOL) ${ }^{19}$ Because metabolic syndrome increases the risk of developing ischaemic heart disease, which causes HF and contributes to its mortality rate, ${ }^{20}$ screening at an early stage is indicated. However, as this study found a limit to screening for HF early in a specific health examination that does not include HF biomarkers, it is evident that an opportunity to provide health guidance is being missed. BNP, NT-proBNP (heart-failure biomarkers), and $\mathrm{Cr}$ are not routinely included in current medical check-up items. Therefore, it would be advantageous to improve medical check-ups through such means as including $\mathrm{Cr}$ checks to help screen for HF patients who must pay high medical costs. More broadly, we need to establish a system that would increase the percentage of HF patients receiving health check-ups. In addition, we can better meet the important public health goal of screening for $\mathrm{HF}$ at an early stage by adding biomarkers to the items of the current specific medical examination list, ${ }^{21} 22$ and through appropriate treatment, severe illness can be prevented. ${ }^{23}$ In future, we need a system which takes into account these characteristics and problems to help optimise medical costs for patients with HF.

\section{Limitations}

In this study, HF was manually defined through a combination of patients' medical histories in order to increase the reliability of an HF diagnosis based on the name of the disease found in health insurance claim data. Although this should have led to a higher accuracy of HF cases in designating HF cases than by merely obtaining the name of the disease from records, this does not necessarily mean that all cases received a definitive diagnosis of HF. Moreover, as the subjects in this study were aged 40 to 74 years, the target age for detailed health examinations, this study does not reflect the medical costs or medical examination results of those under 40 or over 75 years. Despite the obligation of Japanese medical insurers, the percentage of National Health Insurance beneficiaries who undergo health examinations is currently as low as $15.9 \%$. Furthermore, the percentage of HF patients who receive medical examinations is as low as $9.7 \%$, and therefore one limitation of our study is its low generalisability from these specific health examination data.

\section{CONCLUSION}

In this study, we analysed specific health examination results and national health insurance claim data to describe characteristics of HF patients. Regarding high medical costs, we revealed that cardiovascular surgery fees were significantly higher, yet $64 \%$ of which included preventable diseases. HF patients who incurred high medical costs were associated with high levels of $\gamma$-GTP and $\mathrm{Cr}$, and history of smoking assignificant related factors. These results can thus serve as a reference forscreening persons at high risk of $\mathrm{HF}$ and guide to prevent the exacerbation of HF.

Acknowledgements We express our gratitude to Hiroshima City for providing the data and Data Horizon Corporation for assistance processing health insurance receipt sheets. This study was conducted as a joint research project with Hiroshima City and Data Horizon Corporation, Japan. The data were provided by National Health Insurance in Hiroshima City, Hiroshima Prefecture. Hiroshima City requested data cleaning from a receipt-data analysis company (Data Horizon Corporation), and the data were analysed at Hiroshima University. A joint research agreement was signed between Data Horizon Corporation and Hiroshima University, and this study was performed using joint research funds provided by Data Horizon Corporation. We thank the Hiroshima City Insurance and Pension Section for providing us with data.

Contributors Study conception and design and manuscript writing: Yuya Tamaki; Kana Kazawa; Hirohito Watanabe. Literature review/analysis: Yuya Tamaki; Kana Kazawa; Hirohito Watanabe. Manuscript draft writing: Yuya Tamaki; Kana Kazawa; Hirohito Watanabe. Critical revision of methodology: Tantut Susanto; Michiko Moriyama. Preparing draft manuscript: Tantut Susanto; Michiko Moriyama. All authors have declared their consent to the submission the final manuscript.

Funding This study was performed using joint research funds provided by Data Horizon Corporation.

Competing interests None declared.

Patient consent for publication Not required.

Provenance and peer review Not commissioned; externally peer reviewed.

Data availability statement All data in this study received permission from National Health Insurance, Hiroshima City, as part of health-care measures for the insured. Furthermore, the dataset of this study cannot be shared because opt-out was stipulated for data use by the researcher who analysed the data.

Open access This is an open access article distributed in accordance with the Creative Commons Attribution Non Commercial (CC BY-NC 4.0) license, which permits others to distribute, remix, adapt, build upon this work non-commercially, and license their derivative works on different terms, provided the original work is properly cited, appropriate credit is given, any changes made indicated, and the use is non-commercial. See: http://creativecommons.org/licenses/by-nc/4.0/.

ORCID iD

Tantut Susanto http://orcid.org/0000-0002-9685-9869

\section{REFERENCES}

1 Lesyuk W, Kriza C, Kolominsky-Rabas P. Cost-Of-Illness studies in heart failure: a systematic review 2004-2016. BMC Cardiovasc Disord 2018;18:74.

2 Roger VL. Epidemiology of heart failure. Circ Res 2013;113:646-59.

3 Dickstein K, Cohen-Solal A, Filippatos G, et al. Esc guidelines for the diagnosis and treatment of acute and chronic heart failure 2008: the task force for the diagnosis and treatment of acute and chronic heart failure 2008 of the European Society of cardiology. developed in collaboration with the heart failure association of the ESC (HFA) and endorsed by the European Society of intensive care medicine (ESICM). Eur J Heart Fail 2008;10:933-89.

4 Farmakis D, Parissis J, Lekakis J, et al. Acute heart failure: epidemiology, risk factors, and prevention. Rev Esp Cardiol 2015;68:245-8.

5 van Mourik Y, Bertens LCM, Cramer MJM, et al. Unrecognized heart failure and chronic obstructive pulmonary disease (COPD) in frail elderly detected through a near-home targeted screening strategy. $J$ Am Board Fam Med 2014;27:811-21.

6 Ministry of Health, Labour and Welfare of Japan. Standard health examination / health guidance program. Available: https://www. mhlw.go.jp/stf/seisakunitsuite/bunya/0000194155.html [Accessed December 10, 2018.].

7 Tsutsui H, Tsuchihashi-Makaya M, Kinugawa S, et al. Clinical characteristics and outcome of hospitalized patients with heart failure in Japan. Circ J 2006;70:1617-23. 
8 Kazawa K, Rahman MM, Moriyama M. An investigation of factors influencing high usage of medical and long-term care services in an aging society in Japan. Asia Pac J Public Health 2018:30:95-106.

9 Czech M, Opolski G, Zdrojewski T, et al. The costs of heart failure in Poland from the public payer's perspective. Polish programme assessing diagnostic procedures, treatment and costs in patients with heart failure in randomly selected outpatient clinics and hospitals at different levels of care: POLKARD. Kardiol Pol 2013;71:224-32.

10 Bentzon JF, Otsuka F, Virmani R, et al. Mechanisms of plaque formation and rupture. Circ Res 2014;114:1852-66.

11 Mancini GBJ, Gosselin G, Chow B, et al. Canadian cardiovascular Society guidelines for the diagnosis and management of stable ischemic heart disease. Can J Cardiol 2014;30:837-49.

12 Sakata Y, Shimokawa H. Epidemiology of heart failure in Asia. Circ $J$ 2013;77:2209-17.

13 Lu KJ, Kearney LG, Hare DL, et al. Cardiorenal anemia syndrome as a prognosticator for death in heart failure. Am J Cardiol 2013;111:1187-91.

14 Damman K, Valente MAE, Voors AA, et al. Renal impairment, worsening renal function, and outcome in patients with heart failure: an updated meta-analysis. Eur Heart J 2014;35:455-69.

15 Sicras Mainar A, Navarro Artieda R, Ibáñez Nolla J. Economic impact of heart failure according to the effects of kidney failure. Rev Esp Cardiol 2015;68:39-46.
16 Çağı K, Bașar FN, Tok D, et al. How to interpret liver function tests in heart failure patients? Turk J Gastroenterol 2015;26:197-203.

17 Del Gobbo LC, Kalantarian S, Imamura F, et al. Contribution of major lifestyle risk factors for incident heart failure in older adults: the cardiovascular health study. JACC Heart Fail 2015;3:520-8.

18 Sartipy $U$, Dahlström $U$, Edner M, et al. Predicting survival in heart failure: validation of the MAGGIC heart failure risk score in 51,043 patients from the Swedish heart failure registry. Eur $J$ Heart Fail 2014;16:173-9.

19 Nieminen MS, Dickstein K, Fonseca C, et al. The patient perspective: quality of life in advanced heart failure with frequent hospitalisations. Int J Cardiol 2015;191:256-64.

20 Isomaa B, Almgren P, Tuomi T, et al. Cardiovascular morbidity and mortality associated with the metabolic syndrome. Diabetes Care 2001;24:683-9.

21 Ledwidge M, Gallagher J, Conlon C, et al. Natriuretic peptide-based screening and collaborative care for heart failure: the STOP-HF randomized trial. JAMA 2013;310:66-74.

22 Taylor CJ, Roalfe AK, Tait L, et al. Observational longitudinal cohort study to determine progression to heart failure in a screened community population: the echocardiographic heart of England screening extension (ECHOES-X) study. BMJ Open 2014;4:e005256.

23 Coller JM, Campbell DJ, Krum H, et al. Early identification of asymptomatic subjects at increased risk of heart failure and cardiovascular events: progress and future directions. Heart Lung Circ 2013;22:171-8. 